\title{
INFORMED CONSENT THROUGH THE BACK DOOR?
}

\author{
(CASE NOTE: Chester v Afshar [2004] 4 All ER 587)
}

\section{Rob Heywood, Lecturer in Law, Sheffield Hallam University*}

\section{Introduction}

Chester v Afshar ${ }^{1}$ represents the most recent House of Lord's case on the issue of negligent liability for failure to disclose information, and has arguably provided the most significant development in this field since $1985 .^{2}$ Historically, the majority of legal debate has surrounded the standard of care in medical disclosure cases and the amount of information patients are entitled to in order that they can make an informed decision. However, the issue here was one of causation and how, if indeed at all, legal rules can be manipulated as a means of vindicating patient autonomy.

\section{The Facts}

Miss Chester suffered from significant motor and sensory disturbance in her lower body and limbs after a spinal operation carried out by the defendant surgeon, Mr. Afshar. She had been suffering from intolerable back pain for a number of years which had previously been controlled by conservative noninvasive treatment. As a result of serious deterioration of her spinal disks, she agreed to a consultation with Mr. Afshar with a view to the discussion of surgery. It was maintained by the claimant that this appointment was only ever agreed to on the basis that it would be a mere exploratory conversation about the desirability of surgery or otherwise. During the consultation, upon receipt of an MRI scan, Mr. Afshar was of the opinion that continuation of conservative treatment was no longer viable and that surgery was mandatory due to the potential for increasing and severe dilapidation should the condition be left untreated. Accordingly the claimant reluctantly agreed to undergo the recommended procedure at the next available opportunity. The operation was carried out without any negligence on the part of the defendant. However, sadly for Ms. Chester the small risk of cauda equina damage subsequently eventuated leaving the claimant severely disabled. The basis for the claim in negligence centred on Mr. Afshar's failure to disclose this risk and whether it could be proved that this omission had caused Ms. Chester's injury.

At trial the issue of breach of duty was dealt with in a straightforward manner. There was conflicting evidence from both claimant and defendant

\footnotetext{
* R.Heywood@Shu.ac.uk. The author would like to express thanks to Lesley Lomax for her interesting comments and discussions about this case.

1 [2004] 4 All ER 587.

21985 was when the first medical disclosure case was heard before the House of Lords and the majority defined the standard of care within the scope of the Bolam test. Sidaway v Bethlem Royal Hospital Governors [1985] 1 All ER 643.
} 
about the true dynamics of the consultation. The defendant claimed he had discussed all the risks with the patient in accordance with the accepted practice of the profession at the time. This included the risk of cauda equina, haemorrhage and infection. Nevertheless, the patient asserted that she was not given any substantial information about the risks upon which to make an informed choice about whether or not to proceed. She claimed the consultant dismissed her queries about risks in a flippant and off-the-cuff manner in joking 'I haven't crippled anybody yet.' ${ }^{3}$ In situations like this there are often three sides to every story, the claimant's side, the defendant's side, and the truth. This makes it very difficult for the courts to establish what has actually passed between doctor and patient in terms of dialogue and thus it has to be resolved largely on evidential issues. In this case the trial judge clearly felt compelled to believe Ms. Chester. Thus, as the risk stood at roughly one to two per cent, there was no difficulty in concluding that the defendant had breached his duty of care by falling below the reasonable standard of disclosure associated with the profession at the time.

The remaining issue for the court was whether the consultant's omission provided a sufficient basis for establishing a causal link between the breach and the resultant harm. Fundamental legal principle dictates that in order to establish causation it is for the patient to demonstrate, on the balance of probabilities, that had they been given the relevant information about the risks they would have declined the operation. Ordinarily this would not prove too much of a problem where there is sufficient information to reach a conclusion on this issue. That is, where there is enough evidence for the judge to form an opinion as to what the patient would have done. ${ }^{4}$ Yet, in Chester the court was faced with a relatively new set of facts in that they were unable to form a view on the claimant's future conduct.

The trial judge, Taylor $\mathrm{J}$. found in favour of the defendant on the issue of causation stressing that all the patient had to prove was that she would not have undergone the operation on that particular occasion. ${ }^{5}$ The Court of Appeal agreed with this reasoning. The case was subsequently appealed before the House of Lords.

\section{The Dissenting Judgments: Causation and Strict Legal Principles}

The decision from the House of Lords was not unanimous. However, by a majority of three to two the Lords found in favour of the claimant on the issue of causation. The dichotomy of judicial opinion was seemingly based on the distinction between strict legal principles and the underlying policy considerations with which the law is concerned pertaining to justice and fairness.

Based on the facts of Chester, and in applying conventional 'but-for' principles of negligence, legally speaking the claimant should have lost her case. The rationale behind the need to establish causation in order to recover in negligence is relatively straightforward. Damage is the gist of any

3 Ibid., p.600. The facts of the case are set out in the judgment of Lord Hope.

4 See for example the earlier case of McAllister v Lewisham and North Southwark Health Authority [1994] 5 Med LR 343.

5 [2000] WL 33201379. 
negligence action. A claimant is rightly allowed to claim compensation for any harm that is caused as a result of the defendant's negligence. Still, as Lord Bingham suggested: '. . . the corollaries are also true: a claimant is not entitled to be compensated, and a defendant is not bound to compensate the claimant, for damage not caused by the negligence complained of.' 6 This unearths a number of difficulties in regard to causation in negligent disclosure cases. In comparison to the majority of the Lords who found in favour of the claimant, Lord Hoffmann, in attempting to justify a strict legal approach, provided a somewhat narrow analysis of the foundation on which the doctor's duty of disclosure is based. He stated:

"The purpose of a duty to warn someone against the risk involved in what he presupposes to do, or allow to be done to him, is to give him the opportunity to avoid or reduce the risk. If he would have been unable or unwilling to take that opportunity and the risk eventuates, the failure to warn has not caused the damage. It would have happened anyway."

Accordingly, the problem for the claimant in Chester was that she had to establish, on the balance of probabilities, that had the surgeon adequately warned her, she would have taken the opportunity to avoid or reduce the risk, effectively leaving her to prove she would not have had the operation. This she could not do, and actually made no attempt to do, instead preferring honestly to suggest she may well have had the procedure at some time in the future after a second or even third opinion. ${ }^{8}$ Medical evidence suggested the risk of cauda equina developing would have stood at exactly the same even if performed at a later date and by a different surgeon. Thus, as the claimant failed to prove the defendant's breach actually caused her loss or worsened her physical condition, arguably on conventional causation principles the defendant should not have been liable. However, based on a successful Australian case, the claimant's argument was grounded in the fact that all she had to prove was that she would not have had the operation at that particular time and by that particular surgeon. ${ }^{9}$

In a measured rejection of this Lord Hoffmann used the analogy of a casino to illustrate how the law operates. He provided the following analysis:

"In my opinion this argument is about as logical as saying that if one had been told, on entering a casino, that the odds on No. 7 coming up at roulette were only 1 in 37 , one would have gone away and come back next week or gone to a different casino. The question is whether one would have taken the opportunity to avoid or reduce the risk, not whether one would have changed the scenario in some irrelevant detail." 10

Prima facie one can see the logic in this argument. The odds of the risk eventuating would not have altered and, in undergoing the operation at a later date, the patient would not have been able to avoid or reduce the risk. Thus

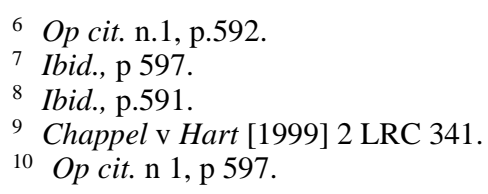


it is possible to conclude that the claimant failed to satisfy the requirements of 'but-for' causation. With respect, this may not be strictly accurate. On reflection it is the issue of the likelihood of the risk occurring at a later date which is in need of further consideration. When analysed through the exact prism of medical disclosure it is possible to view the casino analogy in a different light. Professor Jones illustrates this neatly by turning Lord Hoffmann's argument on its head. He suggests:

... the materialisation of a small random risk. . . is the result of the particular time and circumstances in which the treatment was given (assuming that there is nothing which predisposes the particular patient to this risk), and therefore if treatment had been delayed to another occasion the probability is that the small inherent risk would not have materialised on that occasion, and thus the materialisation of the risk is causally linked to the negligent non-disclosure of risk. ${ }^{11}$

Lord Hoffmann may have fallen into the trap of becoming submerged in an argument based purely on the theoretical ideal of how the law should operate whilst overlooking the actual context and surrounding environment concerning the exact circumstances of the case. It is by virtue of the very fact that the outcome hinges on the uncertainty and imprecise nature of medicine which renders Lord Hoffmann's argument unsustainable. Medical risk disclosure is not a precise science and therefore within this particular context, altering the scenario in some way does actually have a marked effect on the chances of a risk eventuating. As Jones points out, changing the scenario in contemporary medicine has the effect of reducing the chances of a risk materialising. This is because the chances of a small risk eventuating are very much connected to the timing and circumstances of that particular operation. As a result, in delaying the treatment, changing the clinical setting where the procedure takes place or by appointing a different consultant to perform surgery at a later date, the probability of that small risk materialising on that later occasion is reduced.

Therefore whilst it is possible to suggest the judgment in Chester represents a departure from the strict legal principles governing factual causation, if one adopts a pragmatic approach it is still possible to suggest the breach is causally connected to the harm in a broader sense. However, it seems Lord Walker was the only judge who identified the real dangers in Lord Hoffmann's casino analogy ${ }^{12}$ and as such it is apparent the real explanation as to why the majority of the Lords found in favour of the claimant was not based on the above proposition that a causal link actually exists, but rather on a number of wider policy considerations.

11 Jones, M.A. "But-for causation in actions for non-disclosure of risks" (2002) 18 $P N$ 192, p.200

12 Op cit. n.1, p.615. 


\section{Manipulating the Law: The Duty of Disclosure and The Bigger Picture}

In order that the claimant succeeded, it is evident that the remainder of the judges based their arguments on what they perceived to be a deviation from a straightjacket application of 'but-for' principles of causation.

Effectively what the majority of the Lords did was look beyond the immediate concern of establishing a causal connection to address the actual purpose and rationale behind the doctor's duty of disclosure. As we have seen earlier, Lord Hoffmann interpreted this is a restrictive manner and within the confines of strict legal principles. In contrast Lord Hope took a much broader view and suggested:

"The function of the law is to protect the patient's right to choose. If it is to fulfil that function it must ensure that the duty to inform is respected by the doctor. It will fail to do this if an appropriate remedy cannot be given if the duty is breached."13

The recommendation here is that for the law to achieve its purpose, and insofar as the duty of disclosure must have some meaningful content, it is desirable that if breached a remedy must be available to the patient by virtue of this very fact. Lord Hope further stated that: 'The scope of this duty... is unaffected by the response which the patient may give on being told of these risks.' ${ }^{14}$ In acknowledging this and effectively condoning a versatile approach, Lord Hope confirmed causation is very much an ancillary consideration when placed in the wider setting of patient autonomy and the underlying purpose behind enforcing the duty of disclosure. However, a certain degree of perceived manipulation was needed in order to carry this to its conclusion. Some other justification was needed which was more persuasive than the tenuous argument that a causal link actually existed. Lord Steyn, a rather forward thinking judge who has a fondness for academic opinion, found this in Professor Honoré's discussion pertaining to the Australian case of Chappel v Hart. ${ }^{15}$ This was a case with more or less the same facts as Chester where the Australian High Court saw fit to find in favour of the claimant. Whilst conceding on the facts the doctor's failure to warn was not the cause of the injury in the sense that he had not exposed the patient to a risk she need never run nor increased the risk she was bound to run in any event, he suggested:

"Dr Chappel violated Mrs Hart's right to chose for herself, even if he did not increase the risk to her. Judges should vindicate rights that have been violated if they can do so consistently. . . Dr Chappel did cause the harm that Mrs Hart suffered, though not by the advice he failed to giver her. . . Morally he was responsible for the outcome of what he did. . . Do the courts have power in certain cases to override causal considerations in order to vindicate a plaintiff's rights? I

13 Ibid., p.603.

14 Ibid., p.604.

15 Op cit. n.9. 
believe they do though the right must be exercised with great caution." 16

Thus, in Chester Lord Steyn concluded that as a result of the doctor's failure to warn the patient, she had not given a true informed consent in a legal sense. Accordingly 'her right of autonomy and dignity can and ought to be vindicated by a narrow and modest departure from traditional causation principles. ${ }^{17}$ This is where it becomes evident that the crux of the decision was based on policy considerations regarding justice and fairness taking precedent over traditional negligence principles so that the courts could reach a fair outcome for the patient. This is reinforced by Lord Steyn's further comments where he said:

“... I am glad to have arrived at the conclusion that the patient is entitled in law to succeed. This result is in accord with one of the most basic aspirations of the law, namely to right wrongs. Moreover, the decision announced by the House today reflects the reasonable expectations of the public in contemporary society." 18

Within the precise nature of the complaint in Chester, it is this final reference to the 'reasonable expectations of society' which may carry most significance in the medico-legal environment. Therefore it is necessary to analyse this statement through the prism of the potential effect of the case on the domain of patient rights.

\section{Patient Rights and Informed Consent Through The Back-Door?}

Chester represents a continuing trend of cases where policy arguments have prevailed over and above fundamental legal principle. Nevertheless, it is the first time we have seen this in a medical case. ${ }^{19}$ It is a trite observation by Jones that in the six previous medical negligence actions to come before the House of Lords the scores stood at Claimants 0; Defendants 6. ${ }^{20}$ Historically the law has taken the view that the doctor knows-best, more or less allowing the medical profession themselves to dictate the standard of care in negligence. ${ }^{21}$ Thus, in respect of risk disclosure, the courts have subconsciously become embroiled in an almost unquestioning acceptance of medical decision making, thereby creating a paternalistic environment within law. This has now changed somewhat as a result of Chester which represents the first decision by the House of Lords in which the patient has been successful. Indeed it is possible to view the judgment as evidence of a

16 Op cit. n.1, pp.595, 596 quoting from Honoré, T. "Medical non-disclosure, causation and risk: Chappel v Hart" (1999) 7 Torts Law Journal 1, p.8.

17 Ibid., p.596.

18 Ibid., p.597.

19 See Fairchild v Glenhaven Funeral Services Ltd, Fox v Spousal (Midlands) Ltd, Mathews v Associated Portland Cement Manufacturers (1978) Ltd [2002] 3 All ER 305.

20 Jones, M.A. "The Bolam test and the reasonable expert" (1999) Tort Law Review 226, p.236.

21 This is due to the paternalistic nature of the Bolam test. For discussion see Brazier, M. \& Miola, J. "Bye-bye Bolam: A medical litigation revolution" (2000) 8 Med L Rev 85. 
paradigm shift re-enforcing the notion that we are on the precipice of a new dawn for patient rights. ${ }^{22}$

That being said, would it be acceptable to suggest the case has introduced informed consent by the back-door? Probably not. Effectively what the courts have done is endorse a strict liability approach to negligent disclosure cases rendering medical practitioners liable by virtue of the very fact they have breached their duty of disclosure. ${ }^{23}$ This is not a justifiable argument for suggesting informed consent has been introduced in England. Whilst there have been subtle moves towards a prudent patient standard of care, this has not been accepted unequivocally by the courts at the highest level and the types of risks that ought to be disclosed will still inevitably be judged in reference to the accepted practice of the medical profession. ${ }^{24}$ Chester did not specifically consider or alter the standard of care and the English courts have not yet sanctioned the approach endorsed by some North American and Commonwealth jurisdictions. ${ }^{25}$ Notwithstanding this, its real impact may well lie in the fact that the standard of care itself was omitted to be considered in any detail. The risk stood at 1-2 per cent and, in accordance with the accepted standards of the profession, it was made quite clear the consultant had been negligent in failing to disclose this. ${ }^{26}$ This demonstrates a commitment from within the profession towards an enhanced standard of openness and disclosure within the consent process and it is apparent there is a renewed appetite for respecting individual patients when considering what risks to discuss with them. ${ }^{27}$

As Devaney suggests 'in practice the responsibilities of the courts and doctors remain the same as they ever were. The simple function of the law,

22 However, after the recent House of Lord's decision in Gregg v Scott [2005] 2 WLR 268 this assertion may no longer carry the same weight. Here, by a majority of three to two, the House of Lords declined to continue the expansive approach to causation in refusing to recognise liability for the loss of a chance of a more favourable outcome in clinical negligence actions. Nevertheless, this case was not related to information disclosure per se and was more concerned with negligent diagnosis.

23 Indeed Professor Honoré suggests this in his article, $O p$ cit. n.16. However, with respect this may not be totally accurate. Devaney suggests the claimant still has to prove that if provided with the information about risks they would have acted differently and that "the one piece of information which was withheld was that which would have changed their mind". Devaney, S. "Autonomy rules OK" (2005) 13 Med L Rev 102, p.105.

24 The case of Pearce v United Bristol Healthcare NHS Trust (1998) 48 BMLR 118 synthesised the various decisions preceding it and defined the standard of care as an obligation to disclose all 'significant risks'. Whilst the terminology of the reasonable patient was used in this case it is not authority for suggesting the prudent patient standard of care exists in England per se. See Maclean, A. "The doctrine of informed consent: does it exist and has it crossed the atlantic" (2004) LS 386, p.407-410.

25 Canterbury v Spence (1972) 464 F 2d 772 (US); Rogers v Whitaker [1992] 175 CLR 479 (Australia).

26 See Lord Steyn's comments. Op cit. n.1, p.592.

27 Indeed Jones has suggested that 'as professional attitudes to the question of information disclosure change patients will become "entitled" to more information under the Bolam standard. See Jones, M. "Informed consent and other fairly stories" (1999) 7 Med L Rev 103, p.125. 
to right wrongs, has been upheld. All that is new is that patient autonomy really rules. ${ }^{28}$ Whilst this assertion may ring true, it can only be assessed over a matter of time and only when considered in relation to the potential effect Chester may have on both medical practice and litigation levels on the whole.

\section{The Potential Effect of Chester on Litigation and Medical Practice}

The actual effect Chester may have on negligent disclosure cases is somewhat uncertain. Previous situations where the courts have been prepared to deviate from established legal principles, often concerning general negligence cases, have been described as stand-alone judgments confined very much to the specific facts of a case. ${ }^{29}$ Thus, it is very difficult to visualise these cases as having any profound effect on the law of negligence generally. Whilst it is plausible that the liberal approach to causation is limited to information disclosure type $\operatorname{cases}^{30}$, can one really say it is a case confined to its own facts? It is submitted not to the same extent. When faced with the same scenario the temptation for patients, when questioned about their hypothetical conduct, will undoubtedly be to claim they would always have delayed the treatment in order to obtain a second opinion. After this, if all that remains for them to do in order to establish a causal link is to decline to speculate about what course of action they would adopt in the future, it does make it easier for patients and increases their chances of success. Therefore, it is with interest one should view the policy considerations falling at the opposite end of the spectrum. Indeed both Lord Bingham and Lord Hoffmann commented on the undesirability of opening the floodgates and allowing the payment of potentially huge sums of damages where the defendant's action has not actually worsened the condition of the claimant. ${ }^{31}$ Lord Hoffmann suggested an expansive approach would increase the costs of litigation to an extent where the law of tort would an 'unsustainable vehicle' for cases of this kind. ${ }^{32}$ Whilst he also warned of the potential dangers of making the doctor the insurer of any damage he causes regardless of the whether the patient knew of the risk, respectfully it is submitted that this approach is too restrictive. ${ }^{33}$ It fails to take into account the accurate comments made by Devaney that claimants still have to prove that had they been warned they would have acted differently. ${ }^{34}$ Thus, Chester is not the green-light for prospective litigants that many may perceive it to be. Irrespective of this, in situations where policy considerations fall on both sides of the argument, it is contended the greater good must prevail, and in the current climate it is evident considerations pertaining to patient's rights

28 Op cit. n.23, p.107.

29 See comments by Lord Steyn. Op cit. n.1, p.596.

30 In the recent case of Beary v Pall Mall Investments [2005] EWCA Civ 415 the Court of Appeal rejected the attempt to extend the policy considerations in Chester from medical to financial advice. Dyson L.J. (para. 38) stated the extension would be "breathtakingly ambitious, contrary to authority and. . wrong."“

31 Ibid., p.592 per Lord Bingham, p.597 per Lord Hoffmann.

32 Ibid., p.597.

33 Ibid., p.598.

34 Op cit. n.23, p.105. 
take precedent over and above policy considerations concerning economic and flood-gate factors. ${ }^{35}$

The judgment has been greeted with warmth by a number of academic writers and its significance cannot be underestimated. ${ }^{36}$ However, for various reasons as suggested above it still remains very difficult for patients to actually be successful in medical disclosure cases and many of them will inevitably be settled before ever reaching court. As a result the actual effect on litigation levels per se remains to be seen.

The true significance of the decision is bound up in its symbolic nature. The law is supposed to be prescriptive in nature; laying down guidelines for future conduct. Thus, its real power is to be found in the indirect effect that it may have on the medical profession in years to come, where consent may be taken more seriously as a result of the new found judicial recognition of respect for patient's rights. The outcome is likely to be met with distaste from doctors and there is already evidence of growing concern from within the profession. ${ }^{37}$ In all probability it will have the effect of playing up the importance of consent procedures within hospitals by enhancing the recognition that ought to be afforded to the patient's right to be informed. Yet, this is not without its dangers. It is only with a speculative and optimistic eye that one can hope the reasoning of the House of Lords does not encourage defensive medical practice via the medium of excessive risk disclosure. Moreover, that it does not increase the amount of red-tape within modern medicine, and finally, that it does not introduce unnecessarily bureaucratic informed consent procedures which exhaust the therapeutic benefits of the doctrine itself by taking something away from both the patient and consent as a continuing and reciprocal process.

35 For discussion on the changing nature of the law and its attitude towards patient's rights see Lord Irvine "The patient, the doctor, their lawyers and the judge" (1999) 7 Med L Rev 255.

36 See for example Stapleton, J. "Cause-in-fact and the scope of liability for consequences" (2003) 119 LQR 388; Stauch, M. "Taking the consequences for failure to warn of medical risks" (2000) 63 MLR 261; Grubb, A. "Clinical negligence: informed consent and causation" (2002) 10 Med L Rev 322.

37 See NHSLA Risk Alert "Informed Consent" (2004) 4 NHS Litigation Authority; Mathews, J., "Chester v Afshar: does it raise more questions than it answers?" (2005) 11 The AvMA Medical \& Legal Journal 78. 